\title{
A ótica de gestores sobre a humanização da assistência nas maternidades municipais do Rio de Janeiro
}

\author{
H umanization of care in maternity \\ hospitals in Rio de Janeiro \\ from the administrator's perspective
}

Suely Ferreira Deslandes 1

1 Instituto Fernandes Figueira, Fiocruz. Av. Rui Barbosa 716/20 andar, 22250-020, Rio de Janeiro RJ. desland@iff.fiocruz.br
Abstract This research constitutes an exploratory and hermeneutic study of the managers conceptions on the implantation and the identity of the humanization initiatives adopted by the $\mathrm{M} \mathrm{u}$ nicipal Health District of Rio de Janeiro. Its methodology rulered in the narratives analysis of the managers and macro-managers conceptions. It had as pile fourteen interviews, come in six managers who coordinate programs and a manager of each one of the eight municipal maternities. They are analyzed and confronted the policy institution trajectories of humanization to the childbirth and of attention to the very low birth weigh infants. The main meanings attributed by the subjects to the humanization initiatives relate to the 1) quality of the interpersonal relationship between professionals and users; 2) patient rights recognition; 3) democratization of power relations between professionals and patients; 4) demedicalization of the attention to the childbirth; 5) links promotion between family, mother and hospitalized newborn; 6) health professionals valorization. The conclusions discuss the limits, shades and ideological adjustment occurred in the implantation of these policies and in the attributions of meanings to the humanization concept. Key words Humanization, Childbirth humanization, Very low birth weigh infants, Public health policies, $\mathrm{H}$ ealth rights
Resumo Esta pesquisa constitui um estudo exploratório ehermenêutico da ótica de gestores sobre a trajetória de implantação ea identidade das iniciativas de humanização da assistência adotadas pela Secretaria de Saúde do M unicípio do Rio deJaneiro. Sua metodologia se pautou na análise das narrativas e das concepções de gestores e macrogestores. Teve como acervo 14 entrevistas, entre seis gestores que coordenam programas e um gestor de cada uma das oito maternidades municipais. São analisadas e confrontadas as trajetórias de instituição da política de humanização ao parto e de atenção ao recém-nascido de baixo peso. Os principais significados atribuídos pel os sujeitos às iniciativas de humanização se relacionam 1) à qualidade da relação interpessoal entre profissionais eusuários; 2) ao reconhecimento dos direitos do paciente; 3) à democratização das relações de poder entre profissionais e pacientes; 4) à desmedicalização da atenção ao parto e nascimento; 5) à promoção de vínculos entre familiares, mãe e recém-nascidos hospitalizados; 6) à valorização dos profissionais de saúde. As conclusões problematizam os limites, matizes e ajustes ideológi cos ocorridos na trajetória de implantação destas políticas e nas atribuições de sentidos ao conceito de humanização.

Palavras-chave Humanização, H umanização do parto, Recém-nascido de baixo peso, Políticas públicas de saúde, Direitos em saúde 


\section{Introdução}

O debate sobre a humanização da assistência hospitalar envolve uma ampla e controversa polissemia. A primeira indagação de senso comum é questionar o que significaria humanizar uma relação, essencialmente humana, que é a produção do cuidado de saúde. Apesar da associação a reflexões e demandas recentes, o tema da humanização já era debatido e tal termo utilizado há mais de 40 anos.

Revisão bibliográfica de Casate e Correa (2005) revela a existência de artigos produzidos no âmbito da saúde, especialmente da enfermagem, desde os fins da década de 1950. Os principais sentidos atribuídos à humanização do atendimento, desde então, vão desde uma per spectiva caritativa, messiânica de "doar-se ao próximo", até a integração mais recente, a partir dos anos 90, do discurso dos direitos do cidadão em ter acesso a uma atenção de qualidade, inserindo-se no contexto de um projeto político para a Saúde Pública. Se não é possível denominar com precisão o conceito de humanização, os textos, distribuídos em quatro décadas, têm em comum a reflexão sobre as práticas e modelos de atendimento que poderiam ser considerados "desumanizantes", sendo os mais apontados: a) as condições precárias de trabalho que levam a falhas, estresse e defesas psíquicas dos profissionais por um lado, e a longas esperas, dificuldade de acesso e má acoIhida aos pacientes, por outro; b) a vertente positivista da racionalidade biomédica que ignora as necessidades subjetivas, culturais e pessoais dos pacientes, conduzindo a um atendimento impessoal, focado na patologia e não na pessoa que sofre, responsável, portanto, por uma violência simbólica; c) ao uso da tecnologia como substitutivo da relação profissional-paciente, sendo desvalorizadas a comunicação e empatia entre ambos.

No campo da medicina, o auge da reflexão sobre a humanização do atendimento aponta a década de 1970, quando se nota um exercício crítico e autocrítico à racionalidade vigente, à impessoalidade do modelo médico profissional, à falta de informação e de protagonismo dos pacientes diante de sua terapêutica, além das possi bilidades de iatrogenia da prática clínica (destacando-se aí a obra de Illich). Em 1972, já ocorria em São Francisco (EUA) um simpósio nacional intitulado "H umanizando o Cuidado em Saúde", derivando uma publicação com a mesma denominação (H oward \& Strauss,
1975). Para o mesmo período, a base de consulta bibliográfica M edline (considerando somente a década de 1970), a partir da chave de consulta "humanização", registra 37 textos, sendo 28 textos publicados em periódicos de medicina e enfermagem de várias nacionalidades. Sob referências teórico-disciplinares diversas, sociólogos, psicólogos, eticistas, médicos, enfermeiros e arquitetos têm, desde então, debatido a humanização dos cuidados em saúde.

No Brasil estas reflexões vão ser retomadas de forma mais intensa no final da década de 1980, a partir dos amplos movimentos de redemocratização política, no espírito do movimento sanitário e, especialmente, pelo movimento de mulheres, em torno de pautas de direitos sexuais e reprodutivos e das críticas ao modelo médico hegemônico.

Estas reflexões, que até então faziam parte de questionamentos internos ao campo da saúde e à prática de seus profissionais, vão ser incorporadas como um conjunto de diretrizes que constituirão o escopo de diversos programas e políticas de saúde no Brasil a partir da década de 1990. Algumas secretarias municipais e estaduais de Saúde seriam precursoras deste processo, que na década seguinte seria ampliado, atingindo uma abrangência nacional. 0 M inistério da Saúde lançaria o Programa Nacional de H umanização da Assistência H ospitalar, em 2000, que seria substituído pela Política Nacional de Humanização - Humaniza SUS, em 2004; a N orma de Atenção Humanizada do Recém Nascido de Baixo Peso, em 1999-2000; o Programa Humanização do Parto. Humanização no Pré- $N$ atal e N ascimento, em 2002. Tais programas e políticas são acompanhadas da produção de diretrizes técnicas importantes, tais como os manuais Parto, aborto e puerpério. Assistência humanizada à mulher, de 2001 e 0 Atenção humanizada ao recém-nascido de baixo peso - M étodo M ãe Canguru, de 2002, que seria a base de dezenas de cursos para a capacitação de formadores no país.

0 presente artigo objetiva, portanto, no âmbito de uma experiência pioneira, analisar o processo de implantação das políticas de humanização e como este conceito-diretriz vai sendo reinterpretado pelos sujeitos envolvidos em sua implementação. Esta pesquisa constitui um estudo exploratório e hermenêutico da ótica de gestores de saúde sobre a implantação e a identidade das iniciativas de humanização da assistência, adotadas pela Secretaria de Saúde do M unicípio do Rio de Janeiro. A pesquisa focalizou 
as duas frentes mais conhecidas das políticas regionais de humanização: "a humanização do parto" ea "humanização da assistência neonatal".

\section{Metodologia}

Trata-se de um estudo exploratório que buscou descrever processos, resgatar versões sobre fatos e propor inferências explicativas a respeito da constituição da identidade do que se denomina "humanização da assistência" na perspectiva dos gestores de saúde. A análise orientouse por um processo interpretativo crítico dos significados atribuídos pelos sujeitos. Buscouse o triplo movimento de contextualizar sóciohistoricamente as falas, situar seu lugar institucional e os campos de interações de onde partem seus autores (Thompson, 1998).

Trabal har a ótica dos gestores de diferentes níveis hierárquicos constituiu estratégia metodológica para identificar eventuais difer enças entre as concepções e as trajetórias institucionais. Analisar a perspectiva destes dirigentes, muitos deles os protagonistas da criação destas iniciativas no município e no país, permitiria compreender mel hor as diretrizes e as lógicas de sua implementação. Incluir os diretores das unidades de saúde possibilitaria explorar a identidade política que o conjunto dessas iniciativas foi ganhando a partir da mediação entre as orientações do grupo central da Secretaria e a dimensão do cotidiano dos serviços.

Os sujeitos do estudo foram gestores da Superintendência de Saúde Coletiva, dos Programas de Saúde da Criança, da M ulher, da Coordenação de Saúde Integral e uma ex-gerente do Programa de Saúde da Mulher, totalizando seis gestores de al to nível hierárquico, doravante identificados como macrogestores (M G). Também foram incluídos os diretores, ou na sua ausência, um membro da direção de oito das principais maternidades municipais (Leila Diniz, Herculano Pinheiro, Carmela Dutra, Alexander Fleming, Fernando M agalhães, Oswaldo Nazaré, M iguel Couto e Andaraí), identificados apenas como gestores ( $G$ ). Gestores das maternidades foram escol hidos por estas serem as instituições hospitalares que reúnem, ao mesmo tempo, os dois campos das políticas de humanização (da assistência ao parto e ao prematuro). As entrevistas ocorreram entre os últimos meses de 2003 e primeiros de 2004.

A técnica adotada para a construção dos dados foi a entrevista aberta, apenas organizada a partir de alguns tópicos desencadeadores. 0 primeiro propunha aos gestores que contassem a história das iniciativas de humanização, o que propiciou a produção de narrativas e demandou uma análise própria. 0 ponto de partida foi a análise das estruturas, a partir da adaptação da perspectiva Laboviana (M onteiro, 2000). Por limitações editoriais, apresentaremos a estrutura de apenas uma narrativa, buscando retratar, através das avaliações trazi das pelo narrador, os valores atribuídos a si, às ações que constroem o enredo da narrativa (ações complicadoras) e aos demais personagens. 0 restante das narrativas foi tratado coletivamente, priorizando-se, na compilação de seus conteúdos (função ideacional), na forma como foram enunciadas (função textual), as noções de identidade ali construídas, pois ao contar histórias situamos os outros e a nós numa rede de relações e de atribuição de papéis ( função interpessoal) (Riessman, 1993).

O segundo tópico da entrevista demandava ao entrevistado falar sobre como conceituava e identificava um "atendimento humanizado" no cotidiano das maternidades. Estes depoimentos conduziram a um acervo que mesclava as dimensões representacionais, especialmente em seus aspectos cognitivos e valorativos. Este corpus foi tratado a partir dos procedimentos da anál ise temática dos conteúdos, e, a partir de categorizações êmicas e éticas, foram configurados os núcleos de sentido.

Assim, a matéria-prima inicial do estudo, as histórias, opiniões, relatos e reflexões sobre as experiências dos atores, foi submetida a codificações, categorizações, e inferências. Como écomum nos processos interpretativos, permanece a existência de lacunas e contradições, costuradas a partir da primazia da voz do pesquisador na busca de uma inteligibilidade que é sempre artificial e provisória (Geertz, 1989).

\section{Resultados e discussão}

\section{Narrativas inaugurais sobre humanização da assistência}

Contar sobre o começo das iniciativas de humanização nas maternidades não envolve somente "vieses de memória" dos gestores e macrogestores. Não são apenas fatos a serem datados, mas a constituição da imagem de uma trajetória institucional. 0 processo narrativo envolve a construção de enredos peculiares, pois 
cada narrador disporá sua história a partir dos fatos, versões e personagens que invoca numa dada seqüência que é, ao mesmo tempo, biográfica e influenciada pelo acervo das narrativas de seu grupo cultural. A narrativa não é só um modo do pensamento, mas poderoso meio de ordenar a experiência e construir a realidade (M attingly \& Garro, 2000).

As narrativas dos macrogestores situam a década de 1980, o campo da luta pelos direitos reprodutivos femininos e mais tarde a assistência obstétrica como marcos iniciais para as ações que iriam configurar a identidade do que hoje se reconhece como humanização da assistência ao parto.

1 - (Orientação-0)[A gente começou a definir políticas para a M ulher na Secretaria]; 2 (Ação complicadora - AC) [N um primeiro momento o foco foi a questão da contracepção]; 3 (Avaliação-AV) [e somos todas feministas, ]; 4 (AV) [é bom que se diga, não é?]; 5 - (AV) [não sei se a gente ainda assina a carteirinha em baixo]; 6 - (AV) [ mas na época com certeza]; 7 (0-AC) [Então, a xxx, a yyy, eu, depois a zzz, algumas pessoas se agregaram]; 8 - (AC) [Começamos a definir,]; 9 - (0)[naquele momento]; 10 - (0)[no ponto de vista da Secretaria]; 11 (AV) [era importante que as mulheres tivessem direito à contracepção]; 12 - (AC) [então foi 0 que a gente primeiro enfocou]; 13 - (AV)[e é um marco na Secretaria também, à época muito inovadora]; 14 - (0)[Era um grupo de feministas]; 15 - (AV)[ mas um pouco diferente do, grupo maior de feministas]; 16 - (AV) [que nunca se preocupou muito com a questão do nascimento naquela época]; 17 - (AV)[ eu acho até que protestando...]; 18 - (AC)[a história de separar reprodução de sexualidade, o papel da mulher]; 19 - (AC) [ mas nós sempre tínhamos esta questão do nascimento]; 20 - (AV) [ como uma coisa assim que passa por um momento importantíssimo]; 21 - (AV) [um modelo fundamental]; 22 (AV) [ para você ou continuar sendo ou resgatar]; 23 - (Coda-fecho) [Então foi assim que começou] (M G4).

Estes gestores de nível central (mulheres em sua maioria), como se percebe na narrativa acima, contam a história das iniciativas de humanização a partir de um lugar diferenciado. Não falam apenas como administradores de saúde, mas situam sua trajetória a partir da identidade degrupo (alíneas 3, 7, 14 - uso constante do vocábulo "a gente"), oriundo do movimento social, engajado político-ideologicamente no ideário do feminismo (alíneas 3, 4, 14). Capa- zes, contudo, de construir uma postura mais crítica (alínea 5) e flexível deste movimento (alíneas 15, 19). Duplamente inovadoras, seja em relação ao feminismo da época (alíneas 15 a 19), seja em relação às políticas da Secretaria (alíneas 12, 13), avaliam a experiência do parto como tão rica que seria capaz de propiciar a confirmação ou redefinição da identidade feminina (alíneas 19 a 22).

N outras narrativas conta-se que, já à frente da gestão da Secretaria M unicipal do Rio de Janeiro, este grupo participa de um movimento iniciado em Campinas (SP), integrando em 1993 a Rede de H umanização do Parto e N ascimento (Boaretto, 2003). Incorporam, então, 0 debate da violência institucional contra a muIher praticada na assistência ao parto, que neste momento tão crucial de sua vida seria isolada de seus parentes, sem direito a opinar no atendimento dispensado, enfim, tendo seus direitos reprodutivos negligenciados e, portanto, seus direitos humanos postos em cheque ( $\mathrm{Ho}$ tinsky \& Alvarenga, 2002; Diniz, 2001). N arrase a culpabilização que recaía na mulher por ter vivido sua sexualidade e engravidado, quando o poder médico se materializava em exigir que a gestante não manifestasse sentir a dor do parto, "comportando-se bem", sem reclamar do tipo de cuidado recebido. Reconhecem que haveria a continuidade destas formas de violência até o presente em diversas maternidades públicas (M G2).

O debate então já demarcava a importância de garantir à mulher o direito a uma assistência "com dignidade", o que incluía uma intervenção que respeitasse a "fisiologia do parto" (combatendo radicalmente os excessos da medicalização), o direito à escolha de um acompanhante, a privacidade e a opção pelo tipo de parto. 0 termo humanização já circulava nestes meios, mas ainda não era o lema síntese deste processo. Como lembra uma das entrevistadas, a gente utilizava muito, se não me falha a memória, era dignidade e... uma expressão que a gente usava "assistir a mulher pela dignidade e segurança" (M G4).

$N$ arram que nesta época, este grupo gestor vai tomar uma das unidades como o modelo da assistência desejada. Investem-se esforços e afetos na nova maternidade que seria municipalizada e reinaugurada em 1994 com a prerrogativa de encarnar experimentalmente a proposta de uma assistência inovadora. A maternidade Leila Diniz, batizada com o nome da atriz que contestou costumes na década de 1970, nasce- 
ria diferente, pois além das pautas já descritas da "dignidade" e "segurança" no parto, seria a primeira no país a criar normas técnicas e ter regulamentação sobre a humanização do atendimento (Boaretto, 2003). Concederia destaque pioneiro à atuação da enfermagem obstétrica. N esta unidade, como já acontecia na maternidade Fernando M agalhães, grande parte dos partos de baixo risco seria conduzida exclusivamente por enfermeiras. Antecipa, portanto, as iniciativas do M inistério da Saúde, que, visando reduzir as altas taxas de cesárea e valorizar o parto normal, regularia, em 1998, a atuação da enfermagem na assistência ao "parto normal sem distócia" (Portaria M S/GM $2.815,29 / 5 / 1998$ ) (Boaretto, 2003). A nova maternidade representaria, então, um emblema da política da Secretaria, sua aposta e assinatura, além de funcionar como exemplo a ser buscado paulatinamente pelas outras unidades.

Esta trajetória, importante lembrar, não se consolida em seu pionerismo por si só. É, antes de tudo, produzida num contexto histórico da assistência à saúde da mulher e da luta pelos direitos reprodutivos favorável a novos discursos e à experimentação de outros rumos.

0 movimento feminista, durante a década de 1980, tomara a saúde, especificamente a saúde reprodutiva, como um "tema nucleador" de sua atuação, criando um campo de pressão para mudanças nas políticas públicas. Foi também amadurecida uma severa crítica ao saberpoder médico, historicamente vinculado a um discurso disciplinador do corpo feminino, então associado ao lugar da reprodução e de imperfeição biológica. É reconhecida pelos entrevistados, e pela literatura, a influência da obra da feminista e antropóloga Robie Davis-Floyd neste debate.

Discutia-se no país a necessidade de um modelo de assistência fundamentado nos princípios da integralidade e autonomia da mulher (Ávila $\&$ Correia, 1999). A despeito de sua parcial implementação, o Programa de Assistência Integral à Saúde da Mulher, formulado em 1983 e influenciado pelo movimento sanitarista, refletiria boa parte da pauta de reivindicações do movimento de mulheres quanto a uma atenção integral da saúde da mulher em todos os seus ciclos de vida, não se restringindo ao ciclo gravídico puerperal, mas também incluindo a contracepção, como direito, e não como política de controle de fecundidade (Giffin, 2002; Osis, 1998).

N esta mesma década, a Organização M undial de Saúde (OM S) já denunciava os excessos da medicalização do parto, o que ocasionaria "riscos desnecessários" para a saúde da mulher e do bebê (OMS, 1985). Nos anos 80, a OMS realizou três conferências internacionais (Washington, Fortaleza e Trieste) a fim de produzir novos consensos sobre as tecnologias mais apropriadas para o pré-natal, parto e nascimento (Boaretto, 2003). N estas, se apontam como necessário o reconhecimento dos direitos da muIher de ter acesso efetivo a uma assistência de qualidade, que lhe garantisse privacidade, respeito e suporte emocional, devendo a gestante ser vista como partícipe das informações e decisões sobre seu atendimento. Desencadeiam também um movimento de busca de evidências científicas para criar diretrizes claras quanto às melhores abordagens de condução do parto. $\mathrm{No}$ ano de 1996, a O M S Iançou o texto "Assistência ao parto natural", um guia prático compilando, a partir da "medicina baseada em evidências", as práticas comprovadamente úteis, a serem estimuladas; as claramente prejudiciais, a serem erradicadas; as que não existem evidências para apoiar sua utilização, a serem usadas com cautela; e as práticas inadequadamente empregadas, a serem revistas. Em 1998 é publicado o documento " $M$ aternidade segura", revisado e editado para o português em 2003, revelando por parte da OM S um investimento que atravessa duas décadas para a criação de bases e diretrizes para a humanização do parto (OMS, 1996; 2003).

As conferências de defesa dos direitos das mulheres ocorridas no M éxico, Cairo e Beijing dariam visibilidade ampliada a uma agenda internacional dos direitos reprodutivos e sexuais de gozar uma vida sexual plena e saudável, livre de violências e opressões, incluindo a escoIha de ter filhos, com o suporte de uma assistência de saúde de qualidade (Galvão, 1999).

$M$ as, em contraste ao reconhecimento destes direitos, a realidade brasileira era alarmante. A taxa de mortalidade materna no país, no período de 1973-1984 atingia o patamar de 217 óbitos por 100.000 nascidos vivos. Em 1991, ainda que decrescendo para 114 mortes por 100.000, continuavam elevadas as taxas, dado que nos países desenvolvidos, esta era de menos de 10 óbitos (Formiga-Filho, 1999). Apesar da má qualidade do registro, aponta-se que no Estado do Rio de Janeiro, considerando-se o período de 1977 a 1988, as taxas oscilavam de 5 a 11,1 óbitos maternos por 10.000 nascidos vivos, muito acima da taxa tolerável pela OM S $(<5 / 10.000)$ (Silva, 1992). As taxas de cesáreas 
eram também elevadas, permanecendo em níveis crescentes, consideradas "epidêmicas". A Pesquisa N acional sobre Demografia e Saúde, publicada em 1996, indicava que $13 \%$ das muIheres que tiveram filhos até cinco anos antes da pesquisa não tiveram nenhuma consulta de pré-natal. Em 1995 foi informada a média de 1,2 consulta para cada parto ocorrido no SUS (Brasil, 2001).

A qualidade da assistência obstétrica era posta em cheque e se apontava a necessidade de superação desta crise. Como narra uma entrevistada, a assistência era muito ruim nessa época, tinha uma crise de leito muito grande, e aí estava visível a desumanização que envolvia esta assistência, as mulheres peregrinavam, as histórias de violência institucional eram enormes, os bebês morriam porque a gente não tinha um sistema de UTI que funcionasse (M G3).

Assim, se revela a inequívoca contradição entre o reconhecimento da cidadania, dos direitos sexuais e reprodutivos da mulher que a OM S, a política do M inistério (representada pelo PAISM ) e o movimento feminista defendiam e a cruel realidade da mortalidade materna e da assistência precária que as usuárias recebiam. N os meados dos anos 90 , portanto, 0 discurso de humanização do parto encontra um terreno favorável a sua institucionalização como política pública de saúde.

\section{A humanização da assistência neonatal}

As narrativas que contam as iniciativas neste campo da assistência constroem enredos que tomam como ponto de partida a necessidade urgente de minimizar os problemas estruturais da falta de leitos e de condições precárias de atendimentos das UTI neonatais. U ma das gestoras narra o começo desta trajetória a partir da experiência de um hospital em Recife (na realidade, registra-se também o pioneirismo da iniciativa de Santos), que adotou inicialmente o modelo colombiano do método canguru, permitindo que bebês prematuros e recém-nascidos de muito baixo peso, sem leitos ou incubadoras, fossem salvos e ganhassem peso a partir do contínuo contato pele-a-pele com suas mães (posição canguru). Assim, tendo na bagagem um prêmio aferido pelo Banco Nacional do Desenvolvimento Social (BNDES), tal experiência acabou por receber financiamentos desta instituição. Segundo um depoimento, em 1998, a diretoria da área social do Banco teria levado a proposta do projeto Canguru ao ministro da Saúde, como oportunidade privilegiada de, ao mesmo tempo e com baixos custos, salvar bebês e, naquele período em que as mães estão lá, poder dar um monte de educação para as mães, ensinar as mães a fazer artesanato... (M G6). Seria a possibilidade de promover assistência clínica, educação em saúde e "assistência social" num projeto que poderia ser ampliado nacional mente e com custos modestos.

Como se comprova na literatura, em 1999, - BNDES promoveu a Conferência Nacional sobre o M étodo Canguru no Rio de Janeiro e em 2001 se consolidava uma parceria entre este órgão, a Fundação da empresa O rsa e o M inistério de Saúde para disseminar o método nas maternidades de todo país (Lamy, 2003).

Contudo, nas narrativas destas pioneiras se percebe a preocupação em distinguir o modelo colombiano e o modelo nacional, que teria sua identidade diferenciada justamente pelo que identificam como práticas alinhadas à perspectiva de humanização, já em curso no campo da assistência ao parto. M arcam então uma posição política de aderir ao novo modelo, desde que não fosse entendido como substituição de oferta de tecnologia ou barateamento de cuidados intensivos. Esta orientação seria inscrita posteriormente na N orma de A tenção H umanizada do Recém-Nascido de Baixo Peso (Portaria 693 do M inistério da Saúde de 5/7/2000) (Brasil, 2002).

Os neonatal ogistas brasileiros agregariam conhecimentos e práticas para o manejo do estresse e da dor do bebê, para o controle dos efeitos nocivos do ambiente como ruído, luz intensa e incessante e, o mais inovador, concederam especial atenção à promoção do vínculo mãe-bebê, destacando-se também a promoção da amamentação. Assim, como revela uma entrevistada, seria até mesmo possível ter um atendimento humanizado ao prematuro sem, necessariamente, promover a posição canguru estrito senso.

Em 2002 foi então lançado pelo M inistério da Saúde o manual técnico Atenção H umanizada ao Recém- $N$ ascido de Baixo Peso- $M$ étodo $M$ ãe Canguru (Brasil, 2002), enfocando os aspectos psicológicos, biológicos, os cuidados com o prematuro/recém-nascido de muito baixo peso e o acompanhamento ambulatorial.

No Rio de Janeiro esta trajetória não ocorreria descontextualizada do debate da humanização do parto. Não é dizer que ambas iniciativas (humanização do parto e da assistência ao 
bebê de baixo peso / prematuro) tenham caminhado lado a lado, propiciando um atendimento mais "integral" à mulher e ao seu bebê em cada unidade de saúde. Contudo, há uma reflexão mais crítica por parte dos pediatras sobre os significados do nascimento, a partir do ideário do "nascer saudável". É mencionada a influência, relativamente tardia, se comparada ao movimento de mulheres, das obras dos obstetras M ichel O dent e Frederick Leboyer. Assim, mobilizados pela politização da discussão sobre a violência institucional e dos excessos da intervenção médica no momento do parto, os neonatologistas iriam também refletir sobre procedimentos que poderiam ser suprimidos ou adiados, privilegiando um contato mais imediato e afetivo da mãe com o recém-nato.

[...] na medida em que o pediatra foi sendo capacitado mais na questão intensivista, com todos os recursos tecnológicos, na minha opinião ele foi abandonando aquela coisa de pegar o bebê. A gente dessa geração foi capacitada para atender o bebê e tirar do lado da mãe imediatamente, então você quer violência maior queisso? (MG2).

Todavia, no campo da assistência das UTI neonatais não haveria uma pauta contra a "medicalização do atendimento", mas uma busca de racionalizar as intervenções clínicas, visando minimizar o estresse do bebê. 0 grande foco seria associar os aspectos relacionais e psicoafetivos ao cuidado clínico na produção de cuidados, na organização do processo de atendimento.

A trajetória e a identidade deste movimento, seja no campo obstétrico, seja na área neonatal, são, como em qualquer processo ou vivência social, continuamente atualizadas. As interpretações ganham matizes e concepções próprias, moldadas no conjunto das interações concretas e cotidianas dos serviços. Passaremos, a seguir, a trazer as significações atribuídas ao longo do processo de implantação e implementação das práticas de humanização.

\section{"Atendimento humanizado": definições e controvérsias}

0 termo humanização, como se sabe, é extremamente polissêmico, ganhando interpretações de diversos matizes e influências ideológicas. As definições dos gestores se distribuem inicialmente em amplos núcleos de sentido: 1) associados à qualidade da relação interpessoal entre profissionais e usuários (cuidados pautados pelo acolhimento, escuta, empatia, respeito); 2) ligados ao reconhecimento dos direitos do paciente (então interpretados de muitas e distintas maneiras); 3) agregados a uma perspectiva de maior democratização das relações de poder entre profissionais e pacientes; 4) relacionados a um modelo de desmedicalização de atenção ao parto e nascimento; 5) reconhecidos como conjunto de iniciativas para promover o vínculo entre familiares, mãe e recémnascidos hospitalizados e para minimizar o estresse desses bebês; 6) vinculados à valorização dos profissionais de saúde.

\section{Eixo temático 1: relações interpessoais}

No campo das interações, os diversos sentidos de humanização enunciados abrangem significados convergentes, presentes em vários depoimentos. 0 sentido mais reiterado por todos os entrevistados foi de prover acolhimento, um cuidado aberto à escuta, atento às necessidades (sejam psíquicas, culturais ou sociais) da gestante ou da mãe e da família do bebê. Pontuam que esta postura não pode se limitar ao encontro com as equipes diretamente envolvidas na produção da atenção clínica, mas deveria ser adotada por todos os profissionais, desde a recepção do hospital.

N este sentido, estas representações convergem ao que Teixeira (2001) problematiza como essencial à integralidade do cuidado: 0 acolhimento nos serviços, estabelecendo uma rede de conversações. Produzidas a partir de um "acoIhimento dialógico", as conversas seriam a substância por excelência do processo de trabalho em saúde, constituindo técnicas de grande impacto social e elemento indispensável de uma lógica tecnoassistencial capaz de negociar as necessidades de seus usuários e os meios de satisfazêlas.

Também intensamente invocado foi o sentido de humanização como ação empática, assim elucidada por um gestor: de se perguntar eu ia estar satisfeito de receber isso que eu estou dando? (G4). Note-se que há aí uma diferença da empatia representada em outros estudos por profissionais de enfermagem, em que predominava uma vocação religiosa de "amar ao próximo como a mim mesmo" (Vila \& Rossi, 2002). Os gestores, entretanto, parecem tomar o seu referente de satisfação como o parâmetro definidor, ignorando que os usuários, muitas 
das vezes oriundos de outras classes sociais, etnias, gerações, vinculados a lógicas culturais próprias, portadores de experiências anteriores no âmbito do atendimento em saúde, podem ter expectativas e necessidades diferentes das suas.

\section{Eixo 2: "direitos do paciente"}

Em outro eixo, depoimentos afirmam a humanização como uma proposta voltada para o reconhecimento dos direitos dos pacientes, permitindo algumas distinções entre as interpretações dos macrogestores e dos gestores.

0 direito mais consensualmente mencionado como uma prática humanizadora foi o de permitir que a gestante tenha um acompanhante de sua escolha na sala de parto (ainda que todos os entrevistados tenham reconhecido que, na prática, nem sempre isso é cumprido).

Receber informações de forma clara e contínua sobre as etapas do processo de parto e sobre o estado de saúde e terapêutica do bebê internado também foi reconhecido como um direito das gestantes, pais e familiares, especialmente na ótica dos macrogestores.

Ter mais autonomia no processo do trabaIho de parto e no parto também foi apontado pel os macrogestores como direito, materializado na possibilidade de deambular e de escolher a posição mais confortável para permanecer durante o trabal ho de parto e o parto. Note-se, que, na realidade, esta autonomia parece provir da iniciativa do profissional de oferecer um leque de opções possíveis e padronizadas, não sendo mencionada a escuta não diretiva das expectativas das mulheres.

De forma bastante ambígua, não raro, certos depoimentos dos gestores identificam a humanização da assistência como a normatização dos "direitos" da mulher em ficar com o seu bebê imediatamente após o parto, amamentálo e acompanhá-lo caso ele seja internado. Nesta atribuição de sentido, o direito é quase tido como dever de uma "boa mãe" e de um "serviço comprometido com as metas da amamentação" - postura também observada no estudo de Tornquist (2003). N uma entrevista, uma diretora referia que desde o momento da admissão, a gestante (provavelmente com dores e as ansiedades que antecedem ao trabal ho de parto) já era recebida por uma voluntária que estaria "tirando dúvidas" sobre o aleitamento. N outro relato se afirma que quando a mãe sai do lado do leito de seu filho internado, alguém vai averiguar, imediatamente, o motivo de tal ausência.

A concepção de direitos em saúde nos leva a um amplo debate sobre as pautas mínimas ( 0 que é concedido num campo de escassez ou prioridades restritas) e as essenciais (consideradas indispensáveis, dado um patamar de cidadania). Como pontua Puccini \& Cecílio (2004), o direito à saúde, numa leitura radical, contém a possibilidade de as pessoas e grupos terem acesso a informações, usá-las criticamente, criando novos patamares de necessidades e assim buscar mudanças nos projetos, na reorganização e práticas de saúde. Assim, embora haja um contexto de luta social mais ampla, de consciência crítica dos direitos sociais, é no encontro com o cuidador que os direitos à saúde ganham sua materialidade, seja na versão mínima ou essencial; é quando a integralidade pode se estabelecer a partir do reconhecimento das necessidades radicais de cada indivíduo.

\section{Eixo 3: democratização das relações de poder}

Somente abordado por al guns macrogestores foi o sentido da humanização como conjunto de práticas capazes de diminuir a assimetria das relações, corrigindo comportamentos autoritários dos profissionais e permitindo que os usuários, especialmente as gestantes, uma vez bem informados, possam também participar com maior protagonismo nas decisões tomadas pelos profissionais de saúde em seu atendimento. Esta visão não parece ainda estar mais amplamente disseminada entre os gestores das unidades, dado que não foi por eles mencionada.

Esta perspectiva se alinha à ambiciosa e pertinente proposta de mudança da "cultura da assistência", presenteno documento ministerial para a Política N acional de Humanização e na lógica da "decisão compartilhada", a ser cultivada nas relações entre profissionais e pacientes (Brasil, 2004; Deslandes, 2004).

\section{Eixo 4: desmedicalização de atenção ao parto e nascimento}

A humanização do parto e nascimento também foi fortemente associada pelos macrogestores às práticas que minimizem ao máximo as intervenções de obstetras e pediatras num processo que é visto como "natural", "desmedicalizan- 
do" este atendimento. Ponderam que, para tal, é importante ter uma sólida "competência técnica" para discernir entre as intervenções médicas desnecessárias e aquelas que devem ser empreendidas prontamente quando houver necessidade clínica, praticando uma "medicina baseada em evidências", portanto pretensamente livre de "concepções arraigadas".

A análise deste ideário levou alguns estudiosos a criar a hipótese de que o movimento de humanização, como herança do feminismo das décadas de 1960-1970, em contraposição ao parto medicalizado, em que a mulher seria submetida a procedimentos humilhantes, iatrogênicos e impessoais, idealizaria um retorno ao "parto natural" (Tornquist, 2002). N este modelo alternativo, a mulher reaprenderia e resgataria sua competência para gerir seu próprio parto, seguindo uma essência instintiva feminina, poderosa e universal. Neste sentido, concordamos com a autora, vislumbra-se o perigo de se reproduzirem categorias de instinto materno e de natureza, esquecendo a inevitável endoculturação que se dá no processo de parturição (H elman, 1994) e as diferentes demandas de mulheres de classes, etnias e gerações diferentes.

Em contrapartida, os gestores tinham uma leitura controversa sobre o tema da desmedicalização. Associada ao tema e importância do papel do médico na produção dos cuidados para o parto, observou-se a existência, para alguns, de uma radical recusa do termo "humanização". A resistência ao uso do termo é deveras conhecida e se aviva na fala de uma das gestoras quando questiona: nós todos somos seres humanos, o médico lida com o ser humano, e agora este nome humanizar. Nós éramos um tratamento animalesco? (G5). N ote-se a direta associação entre o tratamento dispensado e a própria identidade do médico quando a entrevistada usa o verbo ser ao invés do verbo dar ou equivalente. Este questionamento, pontuado em outras entrevistas, acabou por traçar algumas narrativas, cujo enredo comum foi o de defesa da "boa medicina" sempre praticada pelo narrador(a), pois desde que se formara tratava "com carinho e respeito" seus pacientes, avaliando como um modismo estas "novas idéias".

Como visto na introdução, a reflexão sobre as demandas por práticas consideradas humanizadoras do cuidado de saúde não são novas. Entretanto, é justa a reivindicação pelo reconhecimento de que a medicina, como outras práticas terapêuticas, tem como elemento fun- damental para o exercício de seu mister o desenvolvimento de habilidades narrativas, de ouvir e interpretar as histórias de saúde doença, de vida, enfim, de seus pacientes (H unter, 1991).

Evidencia-se ainda na falas de alguns gestores das maternidades que havia a recusa do termo e da proposta de humanização especialmente quando associada apenas à prerrogativa da equipe de enfermagem em atender os partos de "baixo risco", a quem a política municipal teria supostamente atribuído uma "maior capacidade de conduzir de forma humanizada 0 parto", "desmedicalizando-a" literalmente.

Só o parto por enfermeiras feito pela enfermeira ... éum discurso queeu não gosto. Porquea gente trabalha muito é ... a questão do grupo de saúde, da equipe de saúde, então eu não gosto de fazer sectarismo sexual, de categoria funcional... (G4)

Se em algumas maternidades esta prática era bem incorporada nas relações entre equipes e na divisão do trabalho, noutras constituía arena de embates sutis ou abertos. Como confirmam outros estudos (Tuesta et al., 2004; Boaretto, 2003; Riesco \& Tsunechiro, 2002), este é um tema bastante complexo, que envolve disputas de saber científico, status profissional, atribuições de responsabilidades técnico-institucionais e jurídicas, posição hierárquica e mercado de trabalho. Revela, a existência de conflitos no dia-a-dia das maternidades, como desacordos dos gestores em relação à condução da política de humanização adotada.

\section{Eixo 5: promoção de vínculo entre familiares, mãe e recém-nascidos}

Já a humanização do atendimento aos bebês esteve fortemente associada, pela maioria de ambos os grupos, às iniciativas voltadas para promoção de vínculo entre a mãe e o bebê e seus familiares, permitindo-Ihes permanecer na UTI, estando em contato físico, ocular e sonoro, amamentando quando possível e participando dos seus cuidados. I gualmente enfatizada foi a promoção de cuidados ambientais como controle de luminosidade e ruídos, a fim de respeitar os ciclos de sono e evitar estresse do bebê. $N$ as falas dos gestores se nota uma disseminação e incorporação padronizada do que é preconizado pela literatura recente na temática e pelos manuais oficiais quanto à busca de produção de vínculo mãe- bebê e cuidados ambientais (Brasil, 2002).

Pouco foram mencionadas, e apenas pelos macrogestores, interpretações ligadas ao apoio 
emocional às mães ou de ações voltadas a fortalecer sua rede de suporte social, por exemplo. I sso talvez indique a incorporação ainda parcial no cotidiano dos gestores do ideário proposto, valorizando mais seus aspectos clínicos do que relacionados à dinâmica sociofamiliar.

\section{Eixo 6: foco nos produtores do cuidado}

De todas as representações acerca da humanização, o sentido menos evocado foi aquele que asso cia a humanização da assistência à humanização das condições de trabal ho dos profissionais. A penas duas entrevistas seguiram tal enredo. U ma mencionando a oferta de lanche aos auxiliares de enfermagem que moravam longe do hospital, e assumindo adotar o "plano funcionário", ou seja, garantindo prioridade ao atendimento de funcionários e seus familiares como forma de valorização dos trabalhadores. Se nesta narrativa predomina um tom personalista (a "gestora comprometida"), outra gestora menciona a criação de espaços de escuta de queixas e demandas, além de apoio que a equipe de psicologia proveria aos demais profissionais. M ostra-se aí a diversidade das interpretações, ora numa vertente mais imediatista, ora naquela que incorpora a possibilidade de produzir um modelo gerencial baseado na escuta e participação dos profissionais, quiçá potencialmente capaz de constituir organizações solidárias, a partir de diálogos geradores de compromissos em torno de projetos assumidos coletivamente (Rivera \& Artmann, 2003).

\section{Conclusões}

A análise das narrativas da construção das iniciativas de humanização da assistência ao parto no Rio de Janeiro permite inferir a vitalidade e legitimidade de suas reivindicações, dado que são oriundas do movimento social e não tecnocraticamente aferidas. Por outro lado, observa-se a inevitável porosidade às ideologias que direcionavam o movimento de mulheres, que uma vez destituídas de sua historicidade podem criar uma agenda universal pretensamente aplicável a qualquer mulher.

Leva ainda a refletir sobre os modos de acomodação de um ideário questionador num modelo institucionalizado e historicamente hierárquico, surgindo versões normativas, como também criando resistências daqueles que se vêem ameaçados ou questionados por uma proposta relativamente recente e potencialmente transformadora. Demanda ainda o debate das formas de condução da política de humanização com a categoria médica.

0 contraste com a proposta de humanização do atendimento aos bebês de muito baixo peso / prematuros revela as diferenças entre os papéis que a tecnologia médica desfrutará. No parto (evento considerado não patológico por princípio ideológico) esta tecnologia vai ser questionada e criticada; na humanização do atendimento das UTI, esta será requalificada pela agremiação aos saberes das ciências humanas. Tais diferen ças também conferem papéis distintos aos médicose, conseqüentemente, diversos graus de adesão a tais concepções.

No que concerne às representações dos gestores, o foco relacional parece ser 0 apelo mais amplamente disseminado e aceito como proje to humanizador. U ma vez que diz respeito ao cerne da produção do cuidado em saúde, ou seja, ao encontro entre sujeitos (profissionais e pacientes), aponta importante potencial de mudanças na cultura dos serviços. Contudo, se não for politizado no contexto institucional e no âmbito da crítica eautocrítica do modelo da assistência hospitalar, poderá convergir para uma vertente messiânica, relegada apenas aos piedosos ou vocacionados espiritualmente. Ainda que residam aí posturas moralmente nobres, não será suficiente ter uma empatia a partir do referencial de si mesmo, sob o risco de não se relativizar a melhor acolhida diante dos desejos e expectativas do usuário, deste "outro moral, cultural e social".

Os sentidos atribuídos à humanização como direitos dos pacientes exigem-nos uma reflexão urgente. Concessões dadas pelos profissionais, que também podem ser negadas, mitigadas ou que podem constituir legítimos espaços da cidadania dos usuários? O fertas unilaterais e padronizadas de opções numa autonomia regulada ou aquela baseada no diálogo e escuta não diretiva das expectativas dos usuários? Imposições a aderir aos modelos considerados de forma vertical e assimétrica os "mais saudáveis" ou práticas verdadeiramente negociadas diante dos desejos e possibilidades de cada usuário? A escolha por estas leituras, indubitavelmente, levará à produção de modelos assistenciais muito diferenciados.

Por fim, as concepções dos gestores e macrogestores pouco deram relevo aos produtores do cuidado e às peculiaridades de seu labor, re- 
velando um foco deslocado do processo de trabal ho que, na prática, é por onde se consolidariam "cuidados humanizados". U ma vez abstraídos, imaterializados do seu processo de produção, os cuidados de saúde podem, enganosamente, ser interpretados por uma dimensão unicamente interacional, onde apenas dependeria da vontade e consciência aderir a projetos humanizadores. Leva-nos ainda a pensar a postura dos gestores e a escolha de processos gerenciais que podem apenas adotar o modelo de humanização da assistência de forma burocrática e passageira ou potencializar a adoção de uma lógica de atenção centrada na qualidade das relações humanas, na satisfação e responsividade de usuários e profissionais, no uso racional e compartilhado das tecnologias e na abertura de espaços para um verdadeiro exercício dos direitos dos pacientes.

\section{Referências bibliográficas}

Angulo-Tuesta A, Giffin K, Gama AS, d' Orsi E \& Barbosa GP 2003. Saberes e práticas de enfermeiros e obstetras: cooperação e conflito na assistência ao parto. Cadernos de Saúde Pública 19(5):1425-1436.

Ávila M BM \& Corrêa S 1999. O movimento de saúde e direitos reprodutivos no Brasil: revisitando percursos, pp. 70-103. In Galvão LG \& Díaz J (orgs.). Saúde sexual e reprodutiva no Brasil. Hucitec-Population Council, São Paulo.

Boaretto M C 2003. Avaliação da política de humanização ao parto e nascimento no M unicípio do Rio de Janeiro. Dissertação de mestrado. Escola N acional de Saúde Pública, Fiocruz, Rio de Janeiro.

Brasil 2001. Parto, aborto e puerpério. Assistência humanizada à mulher. M inistério da Saúde/FEBRASCGO/ ABENFO, Brasília.

Brasil 2002. Atenção humanizada ao recém-nascido de baixo peso - M étodo $M$ ãe Canguru. M inistério da Saúde, Brasília.

Brasil (M inistério da Saúde), 2004. Política Nacional de H umanização. Disponível em <http://portal.saude. gov.br/saude/area.cfm?id_area=390>. Acesso em 2004.

Casate JC \& Corrêa AK 2005. H umanização do atendimento em saúde: conhecimento veiculado na literatura brasileira de enfermagem. Rev Lat-Am. Enfermagem 13(1):105-111. 
Deslandes SF 2004. Análise do discurso oficial sobre humanização da assistência hospitalar. Ciência \& Saúde Coletiva 9(1):7-13.

Diniz CSG 2001. Entre técnica e os direitos humanos: possibilidades e limites da humanização da assistência ao parto. Tese de doutorado. Faculdade de M edicina, USP, São Paulo.

Formiga-Filho JFN 1999. Políticas de saúde reprodutiva no Brasil: uma análise do PAISM, pp. 151-164. In Galvão LG \& Díaz J (orgs.). Saúde sexual e reprodutiva no Brasil. Hucitec-Population Council, São Paulo.

Galvão L 1999. Saúde sexual e reprodutiva, saúde da muIher e saúde materna: a evolução dos conceitos no mundo e no Brasil, pp. 165-179. In Galvão LG \& Díaz J (orgs.). Saúde sexual e reprodutiva no Brasil. Hucitec-Population Council, São Paulo.

Geertz C 1989. A interpretação das culturas. Livros Técnicos Científicos, Rio de Janeiro.

Giffin K 2002. Pobreza, desigualdade e equidade em saúde: considerações a partir de uma perspectiva de gênero transversal. Cadernos de Saúde Pública 18(Supl.): 103-112.

H elman C 1984. Cultura, saúde e doença. Artes M édicas, Porto Alegre.

H otinsky SN \& Alvarenga AT 2002. A definição do acompanhante no parto: uma questão ideológica? Estudos Feministas, ano $10,2^{0}$. semestre, 461-481.

H oward J \& Strauss A 1975. H umanizing health care. John Wiley \& Sons, N ova York.

Hunter KM 1991. Doctor's stories. The narrative structure of medical knowledge. Princeton University Press, Nova Jersey.

Lamy ZL 2003. M etodologia Canguru: facilitando o encontro entre o bebê e sua família na UTI neonatal pp. 141-156. In M oreira M EL, Braga N A \& M orsch DS (orgs.). Quando a vida começa diferente. 0 bebêe sua família na UTI neonatal. Fiocruz, Rio de Janeiro.

M attingly C \& Garro LC 2000. Narrative as construct and construction, pp. 1-49. In M attingly C \& Garro LC (org.). N arrative and the cultural construction of illness and healing. University of California Press, Los Angeles.

M onteiro JL 2000. Para compreender Labov. Vozes, Petrópolis.

OM S (World H ealth Organization) 1985. Appropriate technology for birth. Lancet 8452:436-437.

OM S (W orld H ealth Organization) 1996. Care in normal birth: a practical guide. WHO, Genebra.

OM S (W orld H ealth Organization) 2003. Promovendo a maternidade seguira através dos direitos humanos. OM S-Cepia, Rio de Janeiro.
O sis MJM D 1998. PAISM : um marco na abordagem da saúde reprodutiva no Brasil. Cadernos de Saúde Pública 14(Supl. 1):25-32.

Puccini PT \& Cecílio LCO 2004. A humanização dos serviços e o direito à saúde. Cadernos de Saúde Pública 20(5):1342-1353.

Riesco M LG \& Tsunechiro M A 2002. Formação profissional de obstetrizes e enfermeiras: velhos problemas ou novas possibilidades? Estudos Feministas, ano 10, 20. semestre, 449-459.

Riessman CK 1993. Narrative analysis. Sage, Londres.

Rivera JU \& Artmann E 2003. Planejamento e gestão em saúde: flexibilidade metodológica e agir comunicativo, pp. 17-36. In Rivera JU (org.). Análise estratégica em saúde e gestão pela escuta. Fiocruz, Rio de Janeiro.

Silva KS 1992. M ortalidade materna: avaliação da situação do Rio de Janeiro, no período de 1977 a 1987. Cadernos de Saúde Pública 8(4):442-453.

Sloan N L, Leon-Camacho LW, Pinto-Rojas E \& Stern C 1994. Kangoroo mother method: randomized controlled trial of an alternative method of care for stabilized low-birth-weight infants. Lancet 344: 782785.

Teixeira RR 2001. 0 acolhimento num serviço de saúde entendido como uma rede de conversações, pp. 89112. In M attos RA \& Pinheiro R (orgs.). Construção da integralidade: cotidiano, saberes e práticas em saúde. UERJ-Abrasco, Rio de Janeiro.

Thompson JB 1998. I deologia e cultura moderna: teoria social crítica na era dos meios de comunicação de massa. Vozes, Petrópolis.

Toma TS 2003. M étodo mãe-canguru: o papel dos serviços de saúde e das redes familiares no sucesso do programa. Cadernos de Saúde Pública 19(Supl. 2): S233- S242.

Tornquist CS 2003. Paradoxos da humanização em uma maternidade no Brasil. Cadernos de Saúde Pública 19(Supl. 2):S419- S427.

Tornquist CS 2002. Armadilhas da nova era: natureza e maternidade no ideário da humanização do parto. Estudos Feministas, ano 10, 483-492, 2/2002.

Vila VSC \& Rossi LA 2002. O significado cultural do cuidado humanizado em unidade de terapia intensiva: "muito falado e pouco vivido". Rev. Latino-Am. Enfermagem 10(2):137-144.

Artigo apresentado em 18/03/2005

Aprovado em 3/05/2005

Versão final apresentada em 3/05/2005 